\title{
Aloin suppresses lipopolysaccharide-induced inflammation by inhibiting JAK1-STAT1/3 activation and ROS production in RAW264.7 cells
}

\author{
YUNFEI MA $^{1 *}$, TUO TANG ${ }^{1 *}$, LILI SHENG $^{2}$, ZIQIAN WANG $^{1}$, HONG TAO $^{1}$, \\ QING ZHANG $^{1}$, YAO ZHANG ${ }^{1,3}$ and ZHILIN QI ${ }^{1,3}$ \\ ${ }^{1}$ Anhui Province Key Laboratory of Active Biological Macro-Molecules, ${ }^{2}$ Department of Oncology, \\ Yijishan Hospital and ${ }^{3}$ Department of Biochemistry, Wannan Medical College, \\ Wuhu, Anhui 241002, P.R. China
}

Received January 11, 2018; Accepted July 24, 2018

DOI: $10.3892 /$ ijmm.2018.3796

\begin{abstract}
The anti-inflammatory effects of aloin, a bioactive ingredient extracted from Aloe vera, have been described previously. The present study aimed to assess these effects and explore the underlying molecular mechanisms. RAW264.7 cells were incubated with different doses of aloin (100, 150 and $200 \mu \mathrm{g} / \mathrm{ml}$ ) and lipopolysaccharide (LPS; $100 \mathrm{ng} / \mathrm{ml}$ ) for the indicated times. Then, inducible nitric oxide synthase (iNOS) and cyclooxygenase-2 expression levels were detected by western blot analysis and reverse transcription polymerase chain reaction (RT-PCR).The concentrations of inflammatory cytokines in the cell culture supernatant were determined by ELISA. Total nitric oxide (NO) assay and reactive oxygen species (ROS) kits were used to detect NO and ROS levels, respectively. Mitogen-activated protein kinase, nuclear factor $\mathrm{\kappa B}$ and Janus kinase-signal transducer and activator of transcription (JAK-STAT) pathway activation were verified by western blot analysis. Confocal and nucleocytoplasmic separation experiments were used to detect STAT nuclear translocation. It was identified that aloin decreased the level of LPS-induced iNOS expression, inhibiting the release of interleukin (IL)-1 $\beta$, IL-6, tumour necrosis factor- $\alpha$ and NO dose-dependently. Mechanistically, aloin suppressed LPS-induced JAK1-STAT1/3 activation and STAT1/3 nuclear translocation. Additionally, LPS-induced
\end{abstract}

Correspondence to: Professor Yao Zhang or Dr Zhilin Qi, Department of Biochemistry, Wannan Medical College, 22 Wenchang West Road, Wuhu, Anhui 241002, P.R. China

E-mail: zhangyao@ahedu.gov.cn

E-mail: 422627721@qq.com

${ }^{*}$ Contributed equally

Key words: aloin, inflammation, Janus kinase-signal transducer and activator of transcription, lipopolysaccharide, reactive oxygen species
ROS production was inhibited by aloin. Collectively, these data suggest that aloin attenuated LPS-induced inflammation by inhibiting ROS-mediated activation of the JAK1-STAT1/3 signalling pathway, thereby inhibiting the nuclear translocation of STAT1/3 in RAW264.7 cells. The present study provides an experimental basis for the clinical application of aloin in inflammatory-associated diseases.

\section{Introduction}

Inflammation is a protective immune response against bacterial infection or tissue injury. However, excessive inflammation often leads to diseases, including arthritis and sepsis $(1,2)$. The principal components of the outer membrane of gram-negative bacteria are lipopolysaccharides (LPS), also termed endotoxins, which initiate inflammatory immune responses (3). LPS induce inflammatory cytokine release, including interleukin (IL)-6, IL-1 $\beta$ and tumour necrosis factor (TNF)- $\alpha$, via toll-like receptor 4 binding, activating the downstream inflammation-associated signalling pathways $(2,4)$. The signalling pathways of mitogen-activated protein kinases (MAPKs), including extracellular signal-related kinase (ERK)-1/2, p38MAPK, c-Jun NH2-terminal kinase (JNK) and nuclear factor kappa-light-chain-enhancer of activated $\mathrm{B}$ cells (NF- $\mathrm{KB}$ ), have been demonstrated to be involved in LPS-induced inflammatory responses $(5,6)$. The Janus kinase-signal transducer and activator of transcription (JAK-STAT) signalling pathway is an additional important inflammatory signalling pathway activated by LPS $(7,8)$. Following receptor binding, LPS induce JAK phosphorylation, effecting STAT phosphorylation. The phosphorylated STATs form homo-or heterodimers that translocate into the nucleus, regulating the transcription of a number of pro-inflammatory cytokines, chemokines and regulatory enzymes, including inducible nitric oxide synthase (iNOS) and cyclooxygenase-2 (COX-2) $(9,10)$. Increasing evidence has suggested that the inhibition of the JAK-STAT signalling pathway attenuates LPS-induced inflammation $(10,11)$.

Attention has been paid to natural active products, due to their abundance and minimal side effects. The Aloe vera plant 
has been widely used in health and nutritional supplements in Chinese herbal medicine (12). Aloin, a bioactive ingredient extracted from Aloe vera, has been indicated to induce anti-inflammatory (13), antioxidan (12) and antitumour (14-16) effects, neuroprotection (17) and osteoclastogenesis $(18,19)$. However, the anti-inflammatory mechanism of aloin remains unknown.

The present study evaluated the effects of aloin on the LPS-induced inflammatory response and then investigated the underlying molecular mechanism in RAW264.7 cells. It was determined that aloin inhibited LPS-induced TNF- $\alpha$, IL-1 $\beta$, IL-6 and nitric oxide (NO) release, attenuating the iNOS expression induced by LPS. Mechanistically, aloin suppressed reactive oxygen species (ROS)-mediated JAK1-STAT1/3 signalling pathway activation, inhibiting the nuclear translocation of STAT1/3.

\section{Materials and methods}

Reagents and antibodies. LPS from Escherichia coli and aloin (purity $\geq 97 \%$; Fig. 1A) were purchased from Sigma-Aldrich; Merck KGaA (Darmstadt, Germany) and Aladdin Industrial Corporation (Shanghai, China), respectively. The aloin was dissolved in dimethyl sulfoxide and diluted with sterile PBS. DAPI was obtained from Invitrogen; Thermo Fisher Scientific, Inc. (Waltham, MA, USA). Anti-phosphorylated (phosphor)-STAT3 (Tyr705, sc7993) and phospho-IкB (B-9, sc8404) antibodies were obtained from Santa Cruz Biotechnology (Dallas, TX, USA). The antibodies against phospho-p38 MAPK (p-p38 MAPK; Thr180/Tyr182, 4511S), phospho-ERK (Thr202/Tyr204, 4376S), phospho-JNK (Thr183/Tyr185, 4668S), p38 MAPK (8690S), ERK (4695S), JNK (9258S), phospho-JAK1 (Tyr1034/1035, 3331S), phospho-JAK2 (Y1007/1008, 3771S), phospho-STAT1 (Tyr701,9167S), JAK1 (3332S), JAK2 (3230S), STAT1 (14994S), STAT3 (12640S), COX-2 (4842S), iNOS (13120), GAPDH (5174S) and $\beta$-actin (4970S) were purchased from Cell Signaling Technology, Inc. (Danvers, MA, USA). The anti-phospho-IкB (IKK; S176/177, ab194528) antibody was purchased from Abcam (Cambridge, UK). Secondary antibodies coupled to IRDye 800 fluorophore used in the western blot analysis (926-3221 and 926-32210) were obtained from LI-COR Biosciences (Lincoln, NE, USA). The Alexa Fluor ${ }^{\circledR}$ 555 goat anti-rabbit IgG secondary antibody used in the confocal microscopy experiment was obtained from Invitrogen (Z25305; Thermo Fisher Scientific, Inc., Waltham, MA, USA).

Cell culture and passage. Murine macrophage RAW264.7 cells were purchased from Kunming Cell Bank of Type Culture Collection, Chinese Academy of Sciences (Kunming, China) and cultured in high glucose Dulbecco's modified Eagle's medium supplemented with $10 \%$ foetal bovine serum (both Gibco; Thermo Fisher Scientific, Inc.), $100 \mu \mathrm{g} / \mathrm{m}$ streptomycin and $100 \mathrm{U} / \mathrm{ml}$ penicillin at $37^{\circ} \mathrm{C}$ in $5 \% \mathrm{CO}_{2}$. The cells were passaged every 2 days.

Cell viability detection. Cell viability was detected using a Cell Counting Kit-8 (CCK-8; Nanjing KeyGen Biotech Co., Ltd., Nanjing, China) according to the manufacturer's protocol. Briefly, RAW264.7 cells were treated at $37^{\circ} \mathrm{C}$ with different concentrations of aloin $(20,40,80,100,200$ and $400 \mu \mathrm{g} / \mathrm{ml})$ for $24 \mathrm{~h}$ and then incubated at $37^{\circ} \mathrm{C}$ with $10 \mu \mathrm{l} \mathrm{CCK}-8$ working solution for $2 \mathrm{~h}$. The absorbance was detected using a Multiskan $^{\mathrm{TM}}$ GO spectrophotometer (Thermo Fisher Scientific, Inc.) at $450 \mathrm{~nm}$. All experiments were repeated in triplicate, and the data arepresented as mean \pm standard deviation (SD).

Pro-inflammatory cytokine detection. Following a $2 \mathrm{~h}$ pre-treatmentat $37^{\circ} \mathrm{C}$ with different aloin concentrations (100, 150 and $200 \mu \mathrm{g} / \mathrm{ml})$, RAW264.7 cells were seeded at a density of $1 \times 10^{6} /$ well in 12 -well cell culture plates and stimulated with LPS $(100 \mathrm{ng} / \mathrm{ml})$ for $16 \mathrm{~h}$ at $37^{\circ} \mathrm{C}$. The levels of TNF- $\alpha$, IL-1 $\beta$ and IL- 6 in the cell culture supernatants were detected using TNF- $\alpha$ (P06804), IL-1 $\beta$ (P10749) or IL-6 (P08505) ELISA kits (RayBiotech, Inc., Norcross, GA, USA) according to the manufacturer's protocol. The experiments were repeated in triplicate for all aloin concentrations. The results are presented as mean $\pm \mathrm{SD}$.

Nitric oxide detection. RAW264.7 cells were pre-treated at $37^{\circ} \mathrm{C}$ with aloin $(100,150$ and $200 \mu \mathrm{g} / \mathrm{ml})$ for $2 \mathrm{~h}$ followed by a $16 \mathrm{~h}$ LPS treatment. NO production in the cell culture medium was determined using a Total Nitric Oxide Assay kit (Beyotime Institute of Biotechnology, Haimen, China) according to the manufacturer's protocol. The absorbance at $540 \mathrm{~nm}$ was measured using a Multiskan ${ }^{\mathrm{TM}}$ GO spectrophotometer (Thermo Fisher Scientific, Inc.). Each experiment was repeated in triplicate for all aloin concentrations.

ROS determination. RAW264.7 cells were seeded at a density of $2 \times 10^{5} /$ well in 12 -well cell culture plates. Following aloin $(100,150$ and $200 \mu \mathrm{g} / \mathrm{ml})$ pre-treatment at $37^{\circ} \mathrm{C}$, the cells were stimulated with LPS for $30 \mathrm{~min}$, and intracellular total ROS was detected using a Reactive Oxygen Species Assay kit (Beyotime Institute of Biotechnology) according to the manufacturer's protocol. Briefly, following treatment, the cell culture medium was removed, and dichloro-dihydro-fluorescein diacetate (DCFH-DA) was added to a final concentration of $10 \mu \mathrm{M}$. Then, the cells were incubated in a $\mathrm{CO}_{2}$ incubator for $20 \mathrm{~min}$ at $37^{\circ} \mathrm{C}$ and washed 3 times with PBS to completely remove the DCFH-DA from the cells. ROS production was observed by inverted fluorescence microscopy (magnification, x 100; Olympus Corporation, Tokyo, Japan) and quantified using ImageJ software version 1.46 (National Institutes of Health, Bethesda, MD, USA). The experiments were repeated in triplicate.

Nuclear and cytoplasmic protein separation and western blot analysis. The nuclear and cytoplasmic proteins were extracted using a Nuclear and Cytoplasmic Protein Extraction kit (P0028; Beyotime Institute of Biotechnology) according to the manufacturer's protocol. The extraction of total intracellular protein was as follows: Cells were pretreated with aloin $(100,150,200 \mu \mathrm{g} / \mathrm{ml})$ for $2 \mathrm{~h}$, then stimulated with $100 \mathrm{ng} / \mathrm{ml}$ LPS for different times (30 min, 4 or $16 \mathrm{~h}$ ) at $37^{\circ} \mathrm{C}$. Pre-treated RAW264.7 cells were washed twice with ice-cold PBS and lysed in ice-cold cell lysis buffer (P0013; Beyotime Institute of Biotechnology) including $20 \mathrm{mM}$ Tris (pH7.5), $150 \mathrm{mM} \mathrm{NaCl}$, $1 \%$ Triton $\mathrm{X}-100$, sodium pyrophosphate, $\beta$-glycerophosphate, EDTA, $\mathrm{Na}_{3} \mathrm{VO}_{4}$ and leupeptin. Following lysis on ice for $30 \mathrm{~min}$, 
A

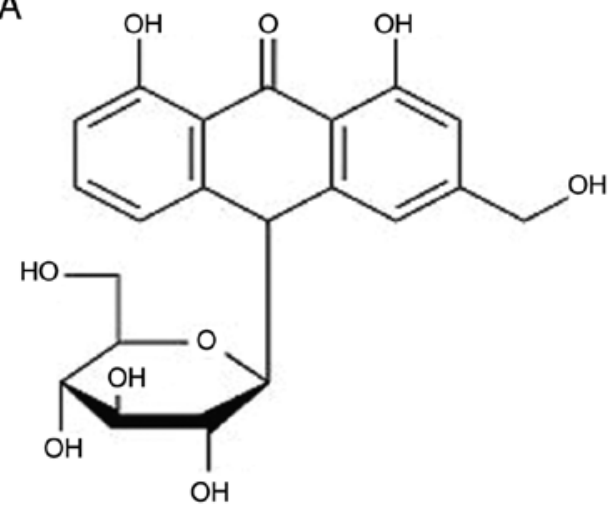

B

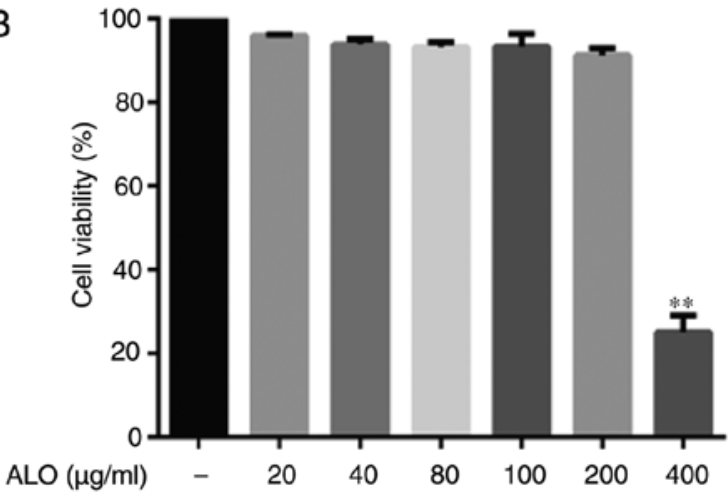

Figure 1. Effect of ALO on RAW264.7 cell viability. (A) Chemical structure of ALO. (B) Cells viability was detected by Cell Counting Kit-8 assay. Data are presented as mean \pm standard deviation of three independent experiments. ${ }^{* *} \mathrm{P}<0.01$ vs. the control group. ALO, aloin.

the lysates were centrifuged $(14,300 \mathrm{xg})$ for $15 \mathrm{~min}$ at $4^{\circ} \mathrm{C}$, and the protein samples were quantified using a BCA/Bradford assay. Then, equal amounts $(50 \mu \mathrm{g})$ of protein were denatured in SDS and electrophoresed on a $12 \%$ SDS-PAGE prior to transferring to a nitrocellulose membrane (Pall Corporation, Port Washington, NY, USA). The membrane was blocked in $5 \%$ skimmed milk dissolved in TBST for $1 \mathrm{~h}$ at room temperature. Following washing with TBS and $0.1 \%$ Tween ${ }^{\circledR}-20$ 3 times, the membrane was incubated overnight at $4^{\circ} \mathrm{C}$ with primary antibodies diluted 1:500 with TBST, followed by incubation with IRDye 800-conjugated IgG secondary antibodies (1:5,000; LI-COR Biosciences) at room temperature for $1 \mathrm{~h}$. The antigen-antibody complex was visualised using an Odyssey ${ }^{\circledR}$ infrared imaging system (LI-COR Biosciences). ImageJ version 1.46 software (National Institutes of Health) was used for the densitometry analysis.

Reverse transcription polymerase chain reaction ( $R T-P C R)$. Intracellular total RNA was extracted from RAW264.7 cells using TRIzol ${ }^{\circledR}$ reagent (Life Technologies; Thermo Fisher Scientific, Inc.), and a RevertAid ${ }^{\mathrm{TM}}$ First Strand cDNA Synthesis kit (Thermo Fisher Scientific, Inc.) was used to synthesise cDNA. The PCR primers were: 5'-GGGTCTTGT TCACTCCACGG-3' (iNOS forward), and 5'-GCTCAGAAC AGCACAAGGGG-3' (iNOS reverse); 5'-GGAGAGTGTTTC CTCGTCCC-3' (GAPDH forward), and 5'-ACTGTGCCGTTG AATTTGCC-3' (GAPDH reverse). The thermocycling conditions were as follows: $94^{\circ} \mathrm{C}$ for $3 \mathrm{~min}$, followed by 30 cycles of $94^{\circ} \mathrm{C}$ for $30 \mathrm{sec}, 55^{\circ} \mathrm{C}$ for $30 \mathrm{sec}, 72^{\circ} \mathrm{C}$ for $1 \mathrm{~min}$ and $72^{\circ} \mathrm{C}$ for $1 \mathrm{~min}$ with a final extension step at $72^{\circ} \mathrm{C}$ for $10 \mathrm{~min}$. The PCR products were detected by agarose gel (1.5\%) electrophoresis and visualized with GoldView (Service Biological Technology Co., Ltd., Wuhan, China). The image was captured by the Gel Doc $^{\text {TM }}$ EZ imager (Bio-Rad Laboratories, Inc., Hercules, CA, USA). ImageJ version 1.46 software (National Institutes of Health) was used for densitometry analysis.

Confocal laser microscopy. RAW264.7 cells were seeded in a small confocal laser dish at 500 cells/well. RAW264.7 cells were pre-treated with $200 \mu \mathrm{g} / \mathrm{ml}$ aloin for $2 \mathrm{~h}$, and then stimulated with LPS for $4 \mathrm{~h}$ at $37^{\circ} \mathrm{C}$. Following treatment, the cells were washed with PBS, fixed with $4 \%$ paraformaldehyde for $30 \mathrm{~min}$ at room temperature, permeabilised with $0.2 \%$ Triton X-100, blocked with $3 \%$ bovine serum albumin in PBS for $1 \mathrm{~h}$ at room temperature and incubated with STAT1 and STAT3 primary antibodies diluted 1:100 with PBS overnight at $4^{\circ} \mathrm{C}$. Following rinsing with PBS, the cells were incubated with a goat anti-rabbit IgG Alexa Fluor ${ }^{\circledR} 555$ conjugated fluorescent secondary antibody diluted 1:200 with PBS for $1 \mathrm{~h}$ in the dark at room temperature. Finally, the cells were stained at room temperature with $0.1 \mu \mathrm{g} / \mathrm{ml}$ DAPI for $3 \mathrm{~min}$ in the dark. Images were captured using a TCS SP8 confocal microscope (magnification, x200; Leica Microsystems GmbH, Wetzlar, Germany).

Statistical analysis. All data were presented as mean \pm standard deviation. Statistical analyses were performed using Prism 6.0 software (GraphPad Software, Inc., La Jolla, CA, USA). The results were analyzed by one-way analysis of variance followed by a post hoc Tukey's test for multiple comparisons. $\mathrm{P}<0.05$ was considered to indicate a statistically significant difference.

\section{Results}

Aloin inhibits LPS-induced iNOS expression in RAW264.7 cells. The present study investigated aloin cytotoxicity using a CCK-8 cell viability assay. Aloin did not affect cell viability, even at a high dose of $200 \mu \mathrm{g} / \mathrm{ml}$ (Fig. 1B). As iNOS and COX-2 are considered to be associated with LPS stimulation (7), the effects of aloin on LPS-induced iNOS and COX-2 expression were investigated. RAW264.7 cells were pre-treated with different doses of aloin for $2 \mathrm{~h}$, then treated with LPS for $16 \mathrm{~h}$, and the iNOS and COX-2 levels were determined by western blot analysis. Aloin treatment suppressed iNOS expression dose-dependently but did not affect COX-2 expression (Fig. 2A). According to these results, aloin concentrations of 100,150 and $200 \mu \mathrm{g} / \mathrm{ml}$ were selected for subsequent experiments. RT-PCR and western blot analyses were used to detect iNOS expression levels in RAW264.7 cells pre-treated with different aloin doses $(100,150$ and $200 \mu \mathrm{g} / \mathrm{ml})$ for $2 \mathrm{~h}$ and then LPS for 6 or $16 \mathrm{~h}$. Aloin markedly attenuated iNOS expression at mRNA and protein levels in a dose-dependent manner (Fig. 2B and C). 
A

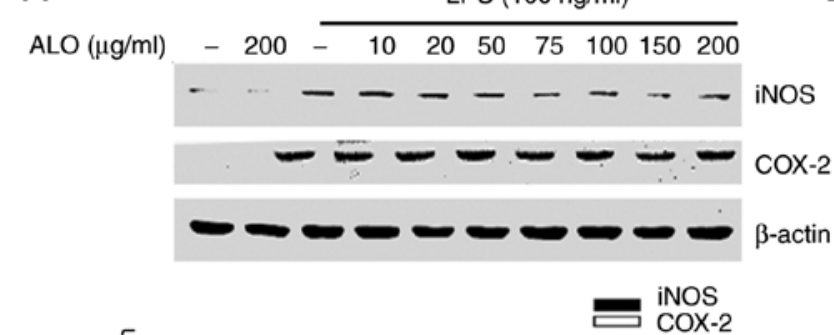

B

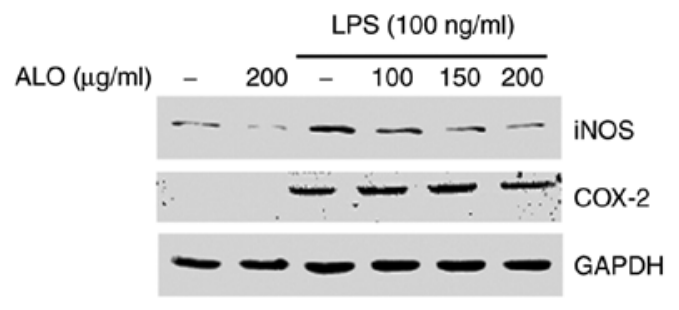

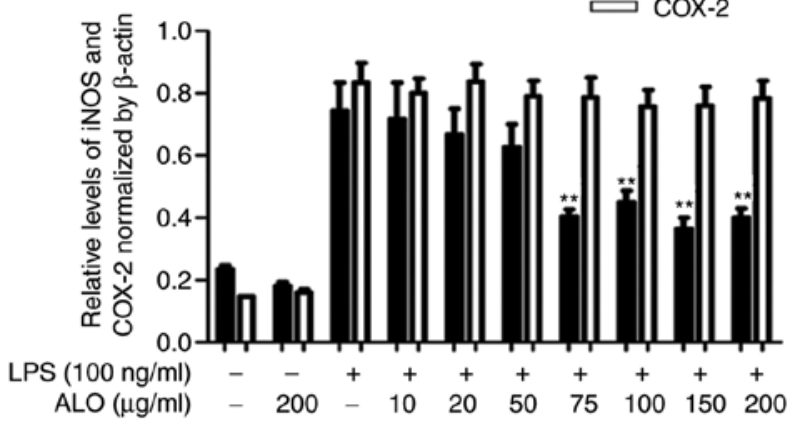

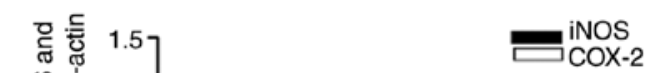

iNOS

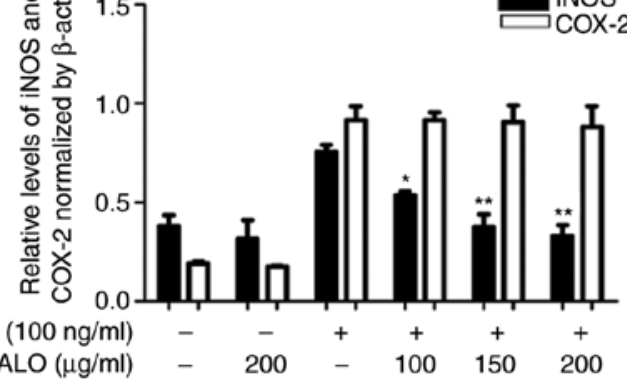

C

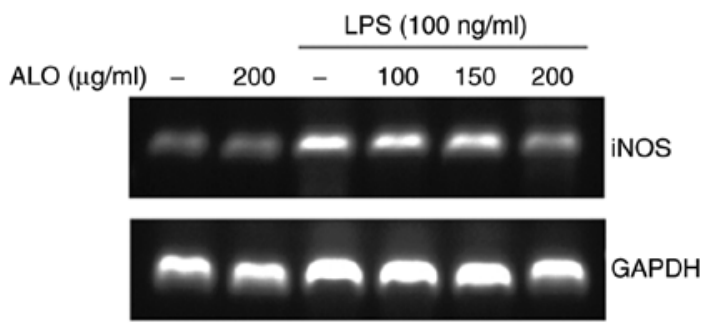

Figure 2. ALO inhibits LPS-induced expression of iNOS, but not COX-2. RAW264.7 cells were pre-treated with (A) different doses of ALO (10, 20, 50, 75, 100, 150 and $200 \mu \mathrm{g} / \mathrm{ml}$ ) for $2 \mathrm{~h}$ or (B) 100, 150 and $200 \mu \mathrm{g} / \mathrm{ml}$ of ALO for $2 \mathrm{~h}$, then stimulated with LPS (100 ng/ml) for $16 \mathrm{~h}$. Following total protein extraction, iNOS and COX-2 levels were determined by western blot analysis. GAPDH or $\beta$-actin was used as a control. (C) RAW264.7 cells were pre-treated with ALO for $2 \mathrm{~h}$, then treated with LPS for $6 \mathrm{~h}$. Total cellular RNA was extracted using TRIzol ${ }^{\circledR}$ reagent, and reverse transcription-polymerase chain reaction was used to quantify the iNOS transcripts. GAPDH was used as a control. Data are presented as mean \pm standard deviation. $\mathrm{P}<0.05$ and ${ }^{* *} \mathrm{P}<0.01$ vs. LPS-stimulated cells. ALO, aloin; LPS, lipopolysaccharide; iNOS, inducible nitric oxide synthase; COX-2, cyclooxygenase-2.

Aloin inhibits the release of pro-inflammatory cytokines and mediators induced by LPS. To investigate the anti-inflammatory effect of aloin, the levels of pro-inflammatory cytokines and mediators, including TNF- $\alpha$, IL-1 $\beta$, IL- 6 and NO in LPS-stimulated RAW264.7 cells were first determined. The obvious increasement of the levels of TNF- $\alpha$, IL-1 $\beta$, IL- 6 and NO resulting from the LPS stimulation were inhibited by aloin in a dose-dependent manner (Fig. 3A-D). Collectively, these results suggest that aloin inhibited pro-inflammatory cytokine and mediator release, exhibiting an anti-inflammatory effect.

Aloin suppresses the LPS-activated JAK1-STAT1/3 pathway, but not the MAPK signalling pathway. It has been suggested that the JAK-STAT, MAPK and NF- $\kappa \mathrm{B}$ signalling pathways are involved in LPS-triggered inflammatory responses $(7,10,20)$. Therefore, to investigate the underlying molecular mechanism of aloin-based inhibition of LPS-induced inflammatory reactions, the effects of aloin on LPS-activated STAT and MAPK signalling pathways were determined. Firstly, the phosphorylation levels of MAPKs and STATs following LPS stimulation of RAW264.7 cells were assessed. LPS stimulation was performed for different time periods, and western blot analysis was used to detect MAPK and STAT activation. At 10 min of LPS stimulation, p38 MAPK, ERK and JNK were activated, peaking at $\sim 30$ min visually (Fig. 4A). To additionally explore the effects of aloin on MAPK phosphorylation induced by LPS, the cells were pre-treated with aloin for $2 \mathrm{~h}$ and LPS for $30 \mathrm{~min}$. Activation was detected by western blot analysis. LPS-induced phosphorylation of p38 MAPK, ERK and JNK were not affected by aloin treatment (Fig. 4B). A previous study demonstrated that NF- $\kappa \mathrm{B}$ became activated following the activation of its upstream kinase IKK and I $\mathrm{B}$ regions $(21,22)$. To explore the effects of aloin on the LPS-induced NF- $\kappa \mathrm{B}$ signaling pathway, levels of I $\mathrm{B}$ kinase (IKK) and I $\kappa$ B phosphorylation were determined by western blot analysis. The results of the present study demonstrated that aloin exhibited a minimal effect on the phosphorylation levels of upstream IKK and $\mathrm{I} \kappa \mathrm{B}$ (Fig. 4C). Therefore, the transcriptional activity of downstream transcription factor $\mathrm{NF}-\kappa \mathrm{B}$ was not examined. STAT1 and STAT3 phosphorylation increased at $0.5 \mathrm{~h}$, peaked at $4 \mathrm{~h}$ and was sustained until $6 \mathrm{~h}$ following LPS stimulation as observed visually (Fig. 4D). The increased levels of STAT1 and STAT3 phosphorylation were markedly decreased by aloin in a dose-dependent manner (Fig. 4E). Collectively, these data 
A
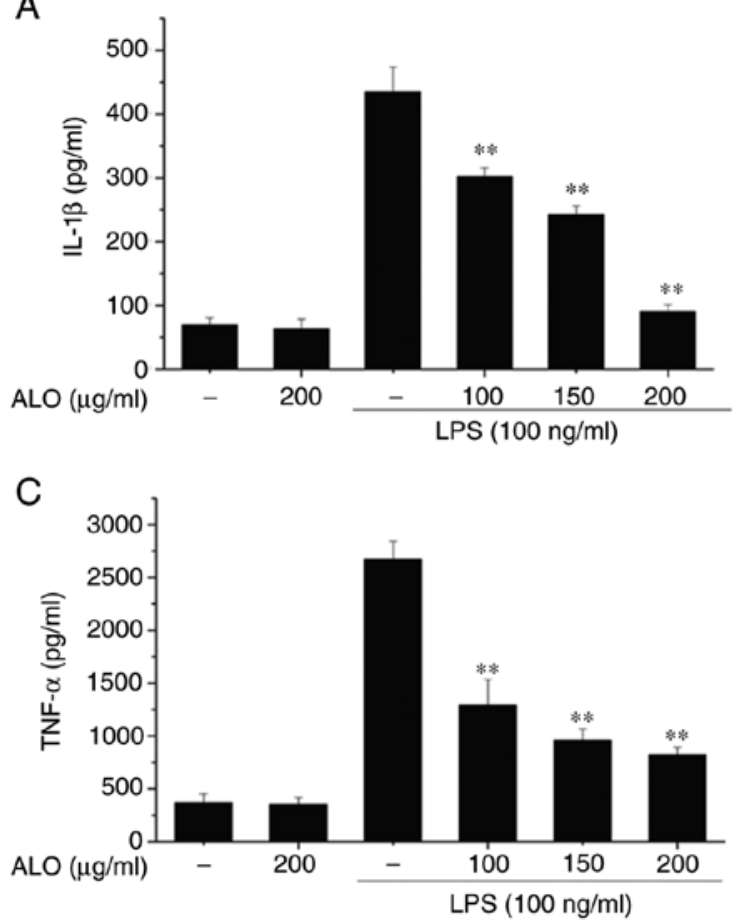
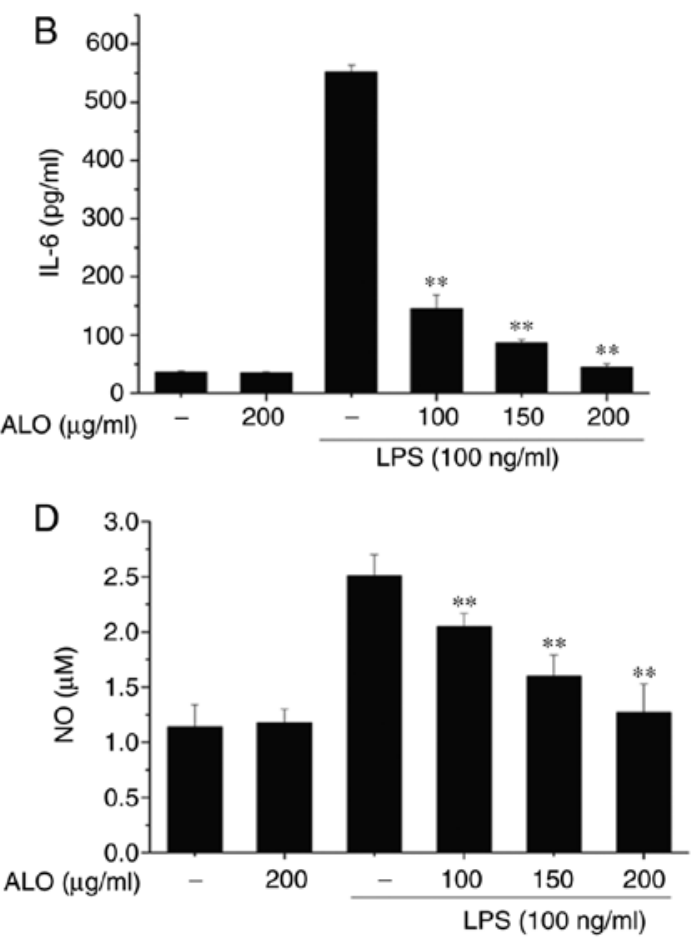

Figure 3. ALO decreased LPS-induced release of pro-inflammatory cytokines and mediators in RAW264.7 cells. RAW264.7 cells were pre-treated with different doses of ALO (100, 150 and $200 \mu \mathrm{g} / \mathrm{ml})$ for $2 \mathrm{~h}$ and treated with LPS (100 ng/ml) for $16 \mathrm{~h}$. The levels of (A) IL-1 $\beta$, (B) IL-6, (C) TNF- $\alpha$ and (D) NO in the cell culture supernatants were detected by ELISA or a total nitric oxide assay, respectively. Data are presented as mean \pm standard deviation of three independent experiments. ${ }^{* *} \mathrm{P}<0.01$ vs. the LPS-stimulated group. LPS, lipopolysaccharide; ALO, aloin; IL, interleukin; TNF- $\alpha$, tumour necrosis factor- $\alpha$; NO, nitric oxide.

suggested that aloin attenuated the LPS-triggered inflammatory response by suppressing STAT1 and STAT3 activation, but not MAPKs, IKK or IкB.

As STAT transcription factors have been determined to be activated by the JAKs (23), the effects of aloin on JAK signals were investigated. RAW264.7 cells were stimulated with LPS for different time intervals, and JAK1 and JAK2 phosphorylation was determined by western blot analysis. JAK1 and JAK2 phosphorylation increased at $5 \mathrm{~min}$ and peaked at $\sim 15$ min following LPS treatment (Fig. 5A). RAW264.7 cells were also incubated with aloin for $2 \mathrm{~h}$ and treated with LPS for 15 min to detect JAK1 and JAK2 activation by western blot analysis. Aloin pre-treatment suppressed LPS-induced JAK1 phosphorylation, whereas JAK2 phosphorylation was not affected (Fig. 5B). Collectively, these results indicated that aloin inhibited STAT1 and STAT3 phosphorylation, potentially via the inhibition of JAK1 in LPS-induced inflammatory responses.

Aloin suppresses LPS-induced STAT1 and STAT3 nucleocytoplasmic translocation. Activated STATs undergo dimerisation and translocate into the nucleus to initiate transcription. Therefore, the present study investigated whether aloin may inhibit the nuclear translocation of phosphorylated STAT1 and STAT3. The cytoplasmic and nuclear proteins of RAW264.7 cells pre-treated with aloin for $2 \mathrm{~h}$ and stimulated with LPS for $4 \mathrm{~h}$ were extracted to determine cytoplasmic and nuclear STAT1 and STAT3 levels. LPS stimulation induced the nuclear translocation of STAT1 and STAT3 and aloin pre-treatment significantly inhibited their nuclear translo- cation (Fig. 6A). A confocal microscopy experiment was performed to detect the location of STAT1 and STAT3. In the control and aloin groups, STAT1 and STAT3 were primarily localised in the cytoplasm, indicated by red staining. In the LPS-treated cells STAT1 and STAT3 transferred into the nuclei, as indicated by blue staining patterns (Fig. 6B and C). However, the levels of nucleocytoplasmic translocation of STAT1 and STAT3 induced by LPS were markedly decreased by aloin. Collectively, the results indicated that aloin inhibited LPS-induced inflammatory responses by suppressing JAK1-STAT1/3 activation and the nuclear translocation of STAT1 and STAT3, at least partially.

Aloin inhibits LPS-induced ROS release. ROS are crucial to LPS-induced inflammation in RAW264.7 cells through the activation of STAT transcription factors (23), and Simon et al (24) suggested that ROS production contributing to JAK-STATs activation. Furthermore, a previous study has revealed that aloin exhibits an antioxidan effect (25). Therefore, the present study investigated whether the anti-inflammatory effect of aloin was due in part to its inhibition of ROS accumulation. RAW264.7 cells were pre-treated with aloin for $2 \mathrm{~h}$ and stimulated with LPS for $30 \mathrm{~min}$. A ROS detection kit was used to assess ROS accumulation. Aloin significantly decreased LPS-induced ROS production in a dose-dependent manner (Fig. 7). The data of the present study demonstrated that aloin may function as an antioxidan. The anti-inflammatory mechanism of aloin may involve the inhibition of ROS-mediated JAK1-STAT1/3 signalling pathway activation. 


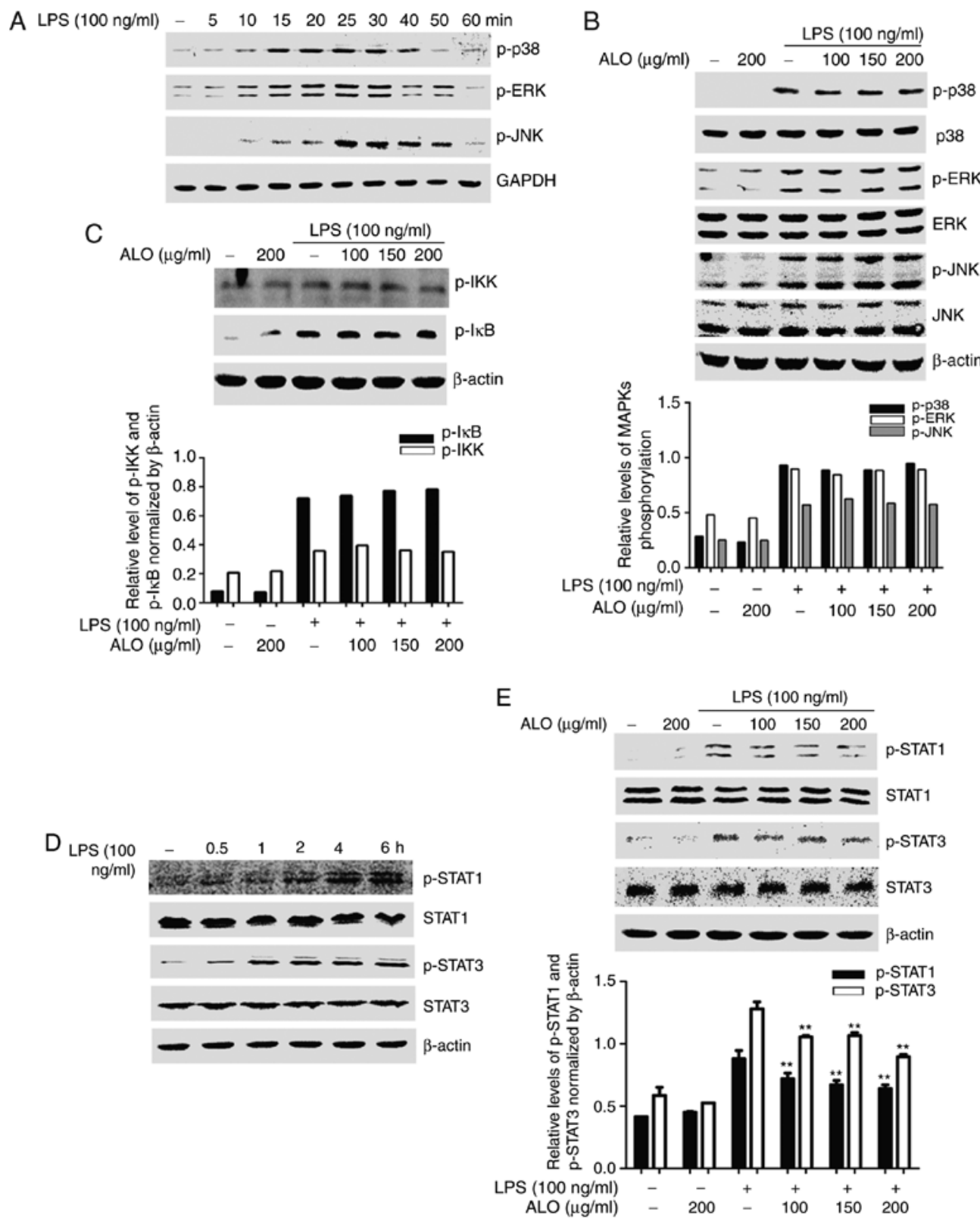

Figure 4. ALO inhibits LPS-activated STAT signalling pathways but does not affect MAPKs, IKK and IкB activation. (A) RAW264.7 cells were stimulated with LPS for different time intervals. (B) RAW264.7 cells were pre-treated with the indicated ALO doses for $2 \mathrm{~h}$ and then stimulated with LPS for 30 min. Proteins were extracted, and p-p38, p-ERK, p-JNK, p-IKK and p-IкB expression levels were detected by western blot analysis using target-specific antibodies. (C) Densitometric analysis of western blot analysis data from (B). The histogram indicates the relative expression of p-p38, p-ERK and p-JNK normalized to total p38, ERK and JNK respectively. (D) STAT1 and STAT3 phosphorylation in RAW264.7 cells stimulated with LPS for different time intervals. (E) STAT1 and STAT3 phosphorylation in RAW264.7 cells pre-treated with indicated doses of ALO for $2 \mathrm{~h}$ and then stimulated with LPS for $4 \mathrm{~h}$. The levels of p-STAT1/3 and total STAT1/3 were measured by western blot analysis. Data arepresented as mean \pm standard deviation. ${ }^{* *} \mathrm{P}<0.01$ vs. LPS-stimulated cells. LPS, lipopolysaccharide; STAT, signal transducer and activator of transcription; p, phosphorylated; MAPK, mitogen-activated protein kinase; p38, p38 MAPK; ERK, extracellular signal-regulated kinase; JNK, c-Jun NH2-terminal kinase; ALO, aloin; IKK, IкB kinase.
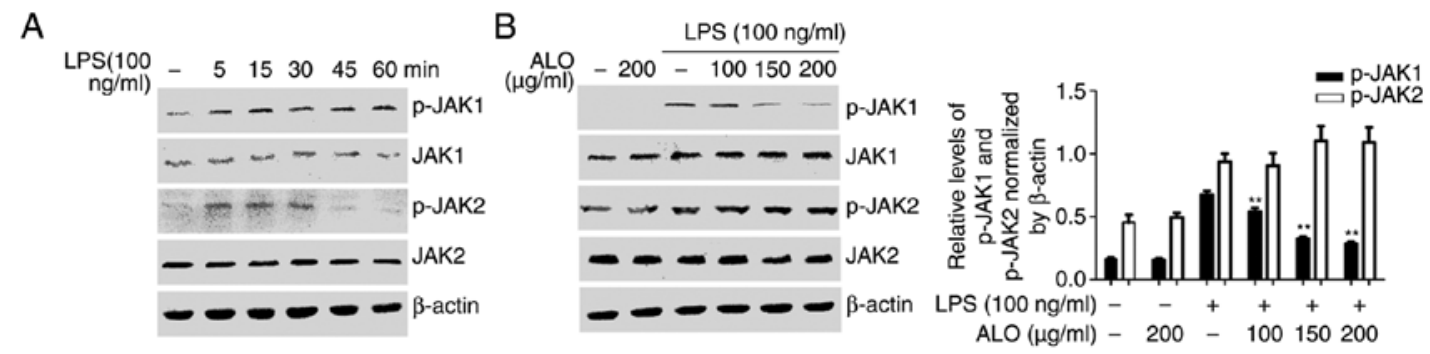

Figure 5. ALO decreases LPS-activated JAK1, but not JAK2. (A) RAW264.7 cells were stimulated with LPS for different time intervals. (B) RAW264.7 cells were pre-treated with indicated doses of ALO for $2 \mathrm{~h}$ and then stimulated with LPS for $15 \mathrm{~min}$. Proteins were extracted, and p-JAK1, p-JAK2, total JAK1 and total JAK2 were detected by western blot analysis. Data are presented as mean \pm standard deviation. ${ }^{* *} \mathrm{P}<0.01$ vs. LPS-stimulated cells. LPS, lipopolysaccharide; JAK, Janus kinase; p, phosphorylated; ALO, aloin. 


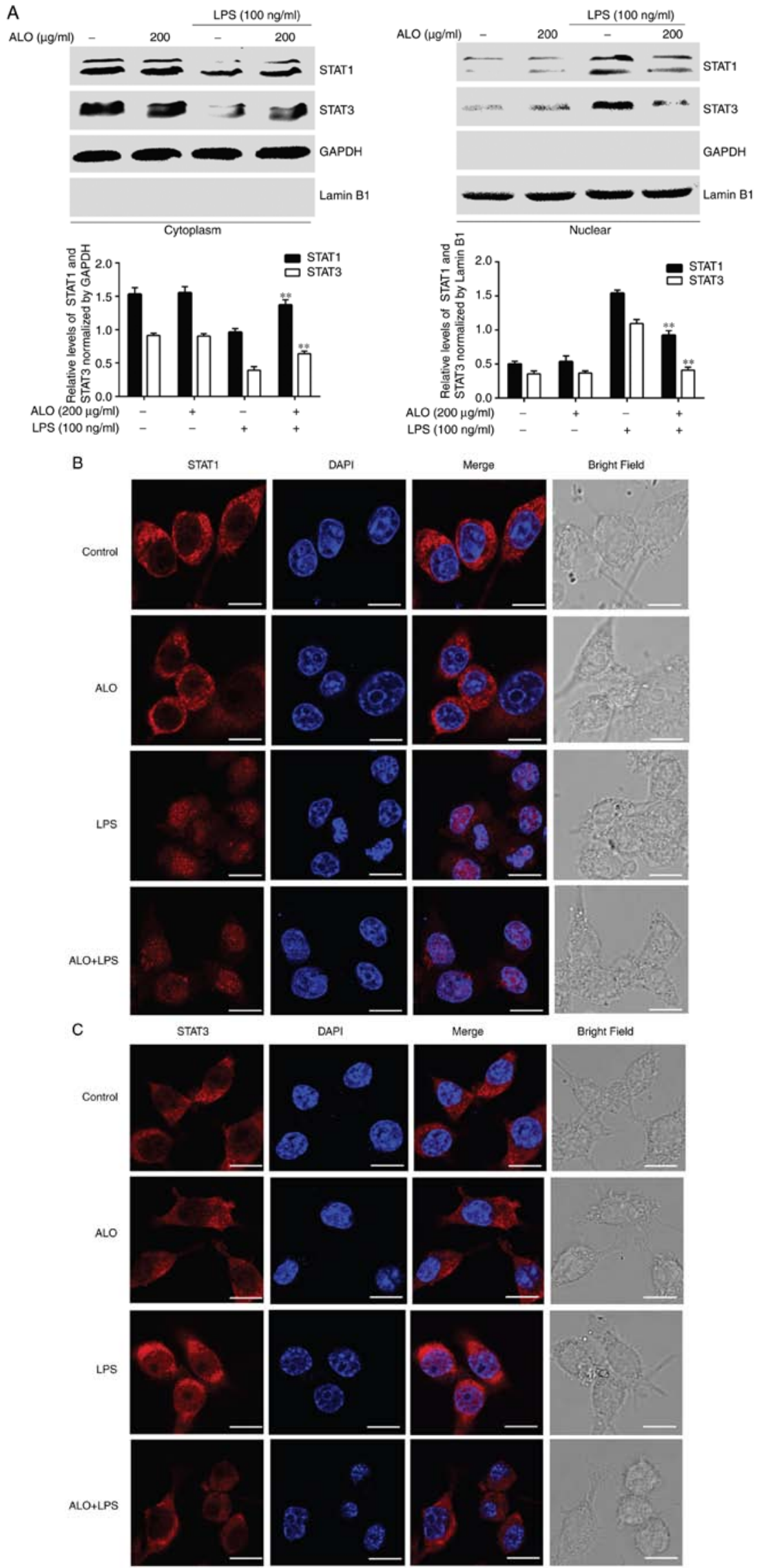

Figure 6. ALO suppresses LPS-induced nuclear translocation of STAT1 and STAT3. RAW264.7 cells were pre-treated with ALO for $2 \mathrm{~h}$ and then stimulated with LPS for $4 \mathrm{~h}$. (A) Nuclear and cytoplasmic proteins were extracted, and STAT1/3 levels were detected by western blot analysis. Data are presented as mean \pm standard deviation. ${ }^{* *} \mathrm{P}<0.01$ vs. LPS-stimulated cells. The nuclear translocation of (B) STAT1 and (C) STAT3 was revealed using confocal laser microscopy. The cells were fixed, permeabilised and incubated with anti-STAT1 and STAT3 antibodies followed by incubation with Alexa Fluor ${ }^{\circledR} 555$ goat anti-rabbit IgG antibody (red). The nuclei were stained with DAPI (blue). Scale bar=25 $\mu \mathrm{m}$. LPS, lipopolysaccharide; ALO, aloin; STAT, signal transducer and activator of transcription. 


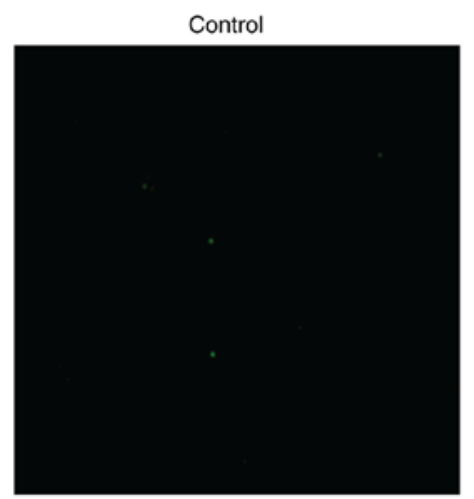

ALO $(100 \mu \mathrm{g} / \mathrm{ml})+\mathrm{LPS}$
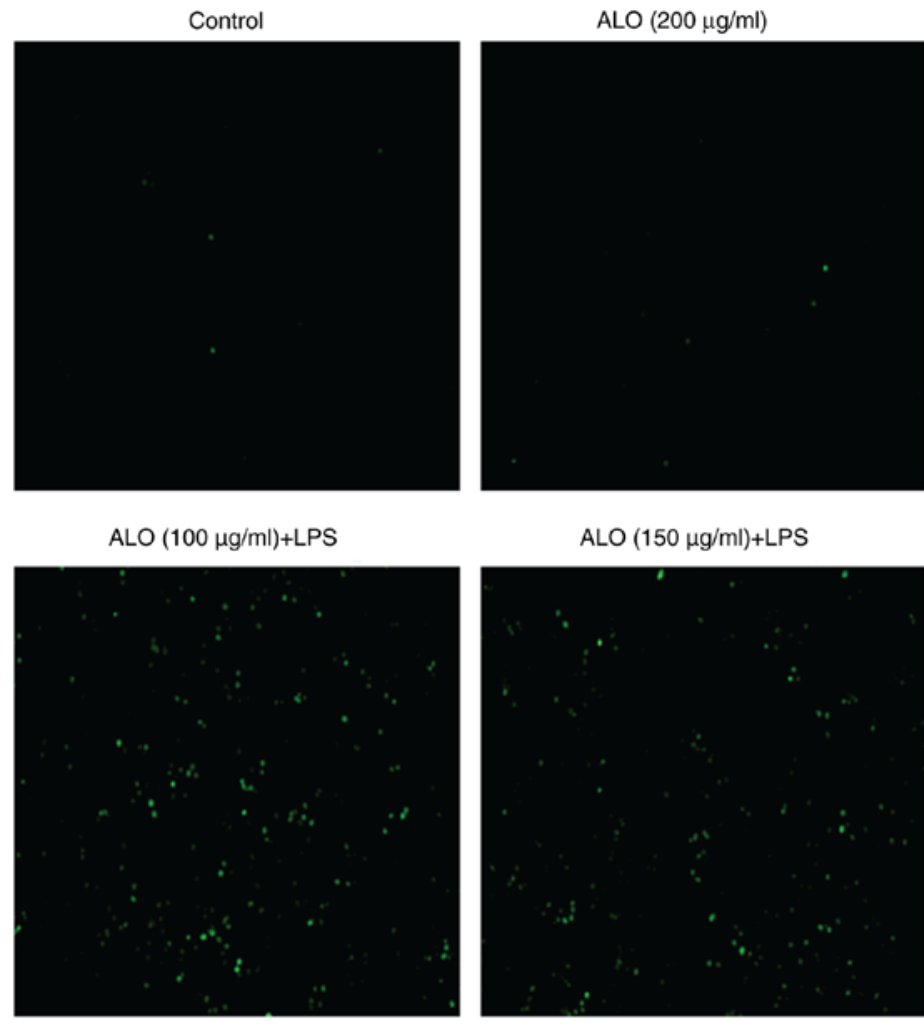

ALO $(150 \mu \mathrm{g} / \mathrm{ml})+\mathrm{LPS}$
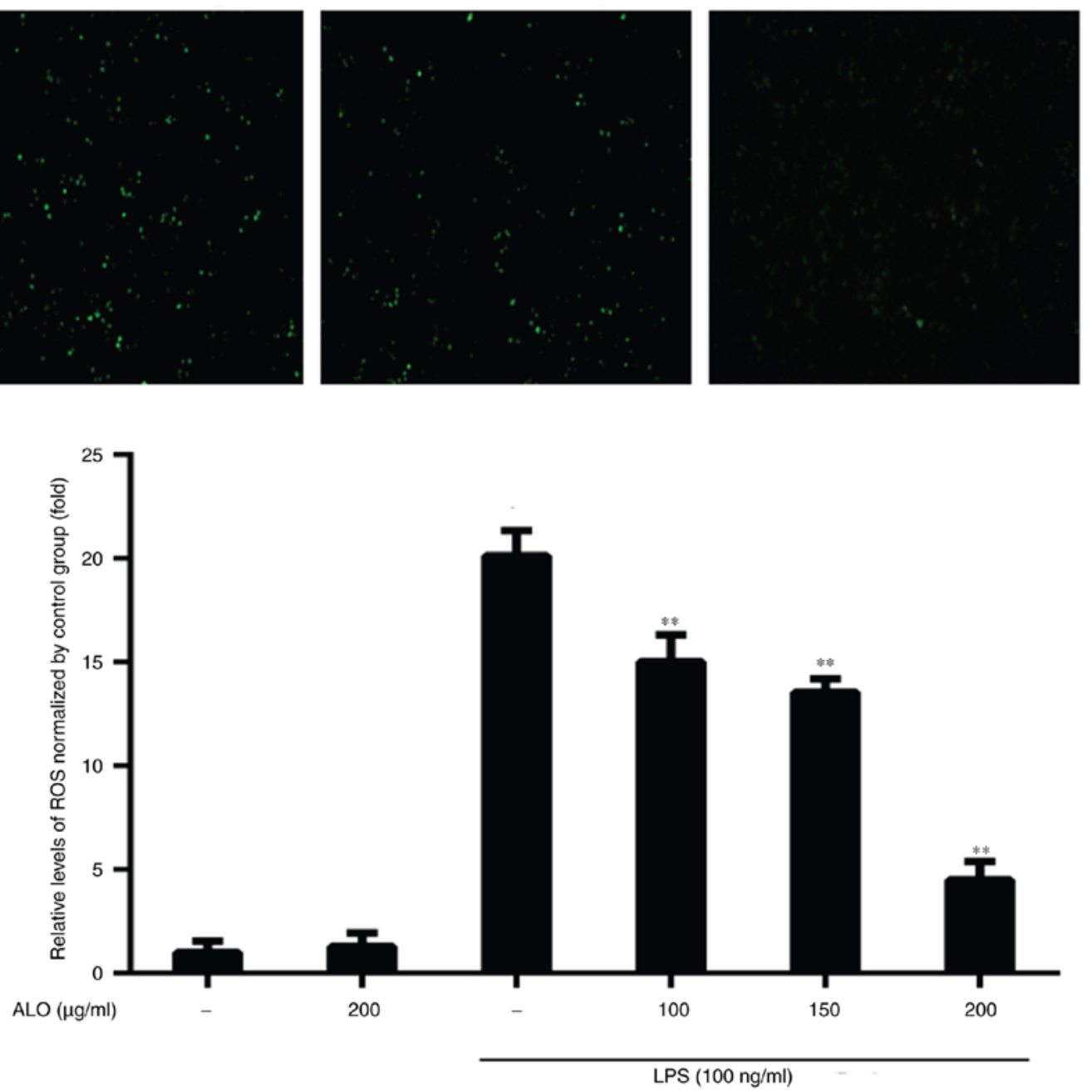

Figure 7. ALO attenuates ROS production induced by LPS. RAW264.7 cells were incubated with ALO for $2 \mathrm{~h}$ and then stimulated with LPS for 30 min. ROS accumulation was determined using a ROS detection kit (magnification, $\mathrm{x} 100$ ). The experiments were repeated in triplicate. ${ }^{* * *} \mathrm{P}<0.01$ vs. the group stimulated with LPS. ALO, aloin; LPS, lipopolysaccharide; ROS, reactive oxygen species.

\section{Discussion}

Inflammation is a protective response. However, the excessive release of pro-inflammatory cytokines from activated macrophages and monocytes causes systemic inflammation (26). As LPS increase the release of pro-inflammatory cytokines, they have been used for several years in the study of this process (27).

Increasing evidence has revealed that a number of bioactive products may antagonise the inflammatory response induced by LPS, having little or no side effects on the human body $(28,29)$. The Aloe vera plant has been widely used in Chinese herbal medicine and extracts have been suggested to possesses anti-inflammatory properties (30). Aloin, the bioactive compound obtained from the leaf exudates of Aloe vera, has been demonstrated to exhibit anti-inflammatory activity $(25,31)$. However, the detailed molecular mechanisms remain unknown. Therefore, the present study investigated the effects of aloin on LPS-stimulated inflammation responses and additionally explored the potential molecular mechanisms. 
To identify aloin cytotoxicity in RAW264.7 cells, the cells were treated for $24 \mathrm{~h}$ with different aloin doses prior to determining cell viability. Aloin did not affect cell viability in RAW264.7 cells at $200 \mu \mathrm{g} / \mathrm{ml}$, suggesting that aloin cytotoxicity from $20-200 \mu \mathrm{g} / \mathrm{ml}$ could be rejected in subsequent experiments.

iNOS and COX-2 are 2 key inflammatory factors, and TNF- $\alpha$, IL-1 $\beta$, IL- 6 and NO are important pro-inflammatory cytokines and mediators in inflammatory disease pathogenesis. The data from the present study revealed that aloin decreased LPS-enhanced iNOS expression at protein and transcript levels in a dose-dependent manner. The release of LPS-induced pro-inflammatory cytokines and mediators were markedly inhibited in a dose-dependent manner. A number of studies have demonstrated the interaction between COX-2 and iNOS, and that NO or its product may activate COX enzymes (32). However, the results of the present study indicated that aloin inhibited iNOS expression and NO release but had no inhibitory effect on COX-2 expression. A potential cause of this discrepancy maybe due to the purity of the aloin used.

To investigate the molecular mechanism, the effects of aloin on LPS-induced inflammatory signalling pathway activation were explored. The JAK-STAT, NF- $\kappa$ B and MAPK signalling pathways have been demonstrated to be involved in inflammation (33). Therefore, the present study aimed to determine whether aloin suppressed the activation of JAK-STAT, NF- $\kappa \mathrm{B}$ and MAPK signalling pathways. It was identified that aloin inhibited JAK1, STAT1 and STAT3 phosphorylation in a dose-dependent manner. As STAT phosphorylation is required for their nuclear translocation and transcriptional activity (34), the effect of aloin on the nuclear distributions of STAT1 and STAT3 in RAW264.7 cells was determined. The nucleocytoplasmic separation experiment and confocal microscopy analysis of the present study revealed that aloin markedly suppressed STAT1 and STAT3 nuclear translocation. Unexpectedly, aloin treatment did not affect the phosphorylation of MAPKs, IKK and I $\kappa$ B induced by LPS. Collectively, the results of the present study suggested that aloin may inhibit the LPS-induced inflammatory response by suppressing the activation of the JAK1-STAT1/3 signalling pathway and the nuclear translocation of STAT1 and STAT3.

Luo et al (35) demonstrated that aloin attenuated LPS-induced NF- $\mathrm{B}$ transcriptional activity by inhibiting its upstream kinase p38 MAPK and mitogen- and stress-activated protein kinase-1. However, the results of the present study demonstrated that aloin pretreatment had no effect on LPS-induced p38 activation. This result was different from that of Luo et al (35). In that study, the inhibitory effect of aloin on p38 MAPK activation was detected $2 \mathrm{~h}$ following LPS stimuli. However, the present study detected the inhibitory effect at $30 \mathrm{~min}$. Therefore, it was hypothesized that the potential reason for the discrepancy is due to the different detection times. Additionally, the present study revealed a novel signal pathway for the anti-inflammatory mechanism of aloin.

It has been demonstrated that LPS stimulation promotes ROS production in macrophages (36), and that ROS serve as secondary messengers capable of regulating pro-inflammatory gene expression (37). Previous studies have indicated the antioxidan properties of aloin $(12,25)$. In the present study, it was identified that aloin decreased ROS accumulation in LPS-stimulated RAW264.7 cells. Furthermore, ROS are potent inducers of various signalling pathways, including MAPK and JAK-STAT pathways (38). Our previous studies demonstrated that $\mathrm{N}$-acetyl-L-cysteine, a ROS inhibitor, suppressed the phosphorylation of JAK-STATs and the expression of iNOS $(6,8)$. These data led us to hypothesize that the inhibitory effect of JAK1-STAT1/3 by aloin may beattributed to its antioxidan activity towards ROS in RAW264.7 cells.

In summary, the present study demonstrated that aloin may partly exert its anti-inflammatory activities through the inhibition of ROS-mediated JAK1-STAT1/3 signalling pathway activation in RAW264.7 macrophages. These results provide novel insight into the anti-inflammatory molecular mechanisms of aloin and provide experimental basis for the clinical application of aloin.

\section{Acknowledgements}

Not applicable.

\section{Funding}

This work was financially supported by grants from the Natural Science Foundation of China (grant no. 81601380), Natural Science Research Project of Anhui Colleges and Universities (grant no. KJ2016SD59); Outstanding Young Talent Support Programme Key Projects of Anhui Colleges and Universities (grant no. gxyqZD2016173), Active Biological Macromolecules Research Provincial Key Laboratory Project (grant no. 1306C083008), Research funding project for college students of Wannan Medical College (grant no. WK2016S24) and College Students' innovation and Entrepreneurship training program project (grant nos. 201710368002 and 201710368166).

\section{Availability of data and materials}

The datasets used and/or analyzed during the current study are available from the corresponding author on reasonable request.

\section{Authors' contributions}

ZQ and YZ designed the experiments, YM, TT, QZ and LS performed this study. ZW and HT analyzed the data. ZQ and YM wrote the paper. All authors read and approved the final manuscript.

\section{Ethics approval and consent to participate}

Not applicable.

\section{Patient consent for publication}

Not applicable.

\section{Competing interests}

The authors declare that they have no competing interests. 


\section{References}

1. Na HS, Song YR, Kim S, Heo JY, Chung HY and Chung J: Aloin inhibits interleukin (IL)-1 $\beta$-stimulated IL-8 production in KB cells. J Periodontol 87: e108-115, 2016.

2. Yu Q, Zeng KW, Ma XL, Jiang Y, Tu PF and Wang XM: Ginsenoside Rk1 suppresses pro-inflammatory responses in lipopolysaccharide-stimulated RAW264.7 cells by inhibiting the Jak2/Stat3 pathway. Chin J Nat Med 15: 751-757, 2017.

3. Guha M and Mackman N: LPS induction of gene expression in human monocytes. Cell Signal 13: 85-94, 2001.

4. Cochet F and Peri F: The role of carbohydrates in the lipopolysaccharide (LPS)/toll-like receptor 4 (TLR4) signalling. Int J Mol Sci 18: E2318, 2017.

5. Chan ED and Riches DW: IFN- $\gamma+$ LPS induction of iNOS is modulated by ERK, JNK/SAPK, and $\mathrm{p} 38^{\text {mapk }}$ in a mouse macrophage cell line. Am J Physiol Cell Physiol 280: C441-C450, 2001.

6. Qi Z, Yin F, Lu L, Shen L, Qi S, Lan L, Luo L and Yin Z: Baicalein reduces lipopolysaccharide-induced inflammation via suppressing JAK/STATs activation and ROS production. Inflamm Res 62: 845-855, 2013.

7. Lee SB, Lee WS, Shin JS, Jang DS and Lee KT: Xanthotoxin suppresses LPS-induced expression of iNOS, COX-2, TNF- $\alpha$, and IL-6 via AP-1, NF- $\mathrm{BB}$, and JAK-STAT inactivation in RAW 264.7 macrophages. Int Immunopharmacol 49: 21-29, 2017.

8. Qi S, Feng Z, Li Q, Qi Z and Zhang Y: Myricitrin modulates NADPH oxidase-dependent ROS production to inhibit endotoxin-mediated inflammation by blocking the JAK/STAT and NOX2/p47phox pathways. Oxid Med Cell Longev 2017: 9738745, 2017

9. Ganster RW, Taylor Bs, Shao L and Geller DA: Complex regulation of human inducible nitric oxide synthase gene transcription by Stat 1 and NF-kappa B. Proc Natl Acad Sci USA 98: 8638-8643, 2001.

10. Zhou Y, Wang J, Yang W, Qi X, Lan L, Luo L and Yin Z: Bergapten prevents lipopolysaccharide-induced inflammation in RAW264.7 cells through suppressing JAK/STAT activation and ROS production and increases the survival rate of mice after LPS challenge. Int Immunopharmacol 48: 159-168, 2017.

11. Qi Z, Qi S, Ling L, Lv J and Feng Z: Salidroside attenuates inflammatory response via suppressing JAK2-STAT3 pathway activation and preventing STAT3 transfer into nucleus. Int Immunopharmacol 35: 265-271, 2016.

12. Liu FW, Liu FC, Wang YR, Tsai HI and Yu HP: Aloin protects skin fibroblasts from heat stress-induced oxidative stress damage by regulating the oxidative defense system. PLoS One 10 e0143528, 2015

13. Park MY, Kwon HJ and Sung MK: Evaluation of aloin and aloe-emodin as anti-inflammatory agents in aloe by using murine macrophages. Biosci Biotechnol Biochem 73: 828-832, 2009.

14. Esmat AY, Said MM and Khalil SA: Aloin: A natural antitumor anthraquinone glycoside with iron chelating and non-atherogenic activities. Pharm Biol 53: 138-146, 2015.

15. Buenz EJ: Aloin induces apoptosis in Jurkat cells. Toxicol In Vitro 22: 422-429, 2008.

16. Wan L, Zhang L, Fan K and Wang J: Aloin promotes A549 cell apoptosis via the reactive oxygen speciesmitogen activated protein kinase signaling pathway and $\mathrm{p} 53$ phosphorylation. Mol Med Rep 16: 5759-5768, 2017.

17. Chang R, Zhou R, Qi X, Wang J, Wu F, Yang W, Zhang W, Sun T, $\mathrm{Li} \mathrm{Y}$ and Yu J: Protective effects of aloin on oxygen and glucose deprivation-induced injury in PC12 cells. Brain Res Bull 121: 75-83, 2016.

18. Pengjam Y, Madhyastha H, Madhyastha R, Yamaguchi Y,

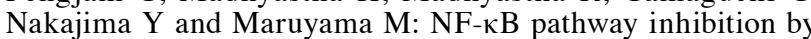
anthrocyclic glycoside aloin is key event in preventing osteoclastogenesis in RAW264.7 cells. Phytomedicine 23: 417-428, 2016.

19. Peng jam Y, Madhyastha H, Madhyastha R, Yamaguchi Y, Nakajima $\mathrm{Y}$ and Maruyama M: Anthraquinone glycoside aloin induces osteogenic initiation of MC3T3-E1 cells: Involvement of MAPK mediated wnt and bmp signaling. Biomol Ther 24 $123-131,2016$

20. Han BH, Lee YJ, Yoon JJ, Choi ES, Namgung S, Jin XJ, Jeong DH, Kang DG and Lee HS: Hwangryunhaedoktang exerts anti-inflammation on LPS-induced NO production by suppressing MAPK and NF- $\kappa \mathrm{B}$ activation in RAW264.7 macrophages. J Integr Med 15: 326-336, 2017.
21. Achoui M, Appleton D, Abdulla MA, Awang K, Mohd MA and Mustafa MR: In vitro and in vivo anti-inflammatory activity of 17-Oacetylacuminolide through the inhibition of cytokines, $\mathrm{NF}-\kappa \mathrm{B}$ translocation and IKK $\beta$ activity. PLoS One 5: e15105, 2010.

22. Qi S, Xin Y, Guo Y, Diao Y, Kou X, Luo L and Yin Z: Ampelopsin reduces endotoxic inflammation via repressing ROS-mediated activation of $\mathrm{PI} 3 \mathrm{~K} / \mathrm{Akt} / \mathrm{NF}-\kappa \mathrm{B}$ signaling pathways. Int Immunopharmacol 12: 278-287, 2012.

23. Pan X, Cao X, Li N, Xu Y, Wu Q, Bai J, Yin Z, Luo L and Lan L: Forsythin inhibits lipopolysaccharide-induced inflammation by suppressing JAK-STAT and p38 MAPK signalings and ROS production. Inflamm Res 63: 597-608, 2014

24. Simon AR, Rai U, Fanburg Bl and Cochran BH: Activation of the JAK-STAT pathway by reactive oxygen species. Am J Physiol 275: C1640-C1652, 1998.

25. Cui Y, Ye Q, Wang H, Li Y, Xia X, Yao W and Qian H: Aloin protects against chronic alcoholic liver injury via attenuating lipid accumulation, oxidative stress and inflammation in mice. Arch Pharm Res 37: 1624-1633, 2014.

26. Balk RA: Systemic inflammatory response syndrome (SIRS): Where did it come from and is it still relevant today? Virulence 5: 20-26, 2014.

27. Mueller M, Hobiger S and Jungbauer A: Red clover extract: A source for substances that activate peroxisome proliferator-activated receptor alpha and ameliorate the cytokine secretion profile of lipopolysaccharide-stimulated macrophages. Menopause 17: 379-387, 2010.

28. Fylaktakidou KC, Hadjipavlou-Litina DJ, Litinas $\mathrm{Ke}$ and Nicolaides DN: Natural and synthetic coumarin derivatives with anti-inflammatory/antioxidant activities. Curr Pharm Des 10: 3813-3833, 2004

29. Mueller M, Hobiger S and Jungbauer A: Anti-inflammatory activity of extracts from fruits, herbs and spices. Food Chem 122 987-996, 2010

30. Akaberi M, Sobhani Z, Javadi B, Sahebkar A and Emami SA Therapeutic effects of Aloe spp. in traditional and modern medicine: A review. Biomed Pharmacother 84:759-772, 2016.

31. Patel DK, Patel K and Tahilyani V: Barbaloin: A concise report of its pharmacological and analytical aspects. Asian Pac J Trop Biomed 2: 835-838, 2012.

32. Swierkosz TA, Mitchell JA, WarnerTD, Botting RM and Vane JR: Co-induction of nitric oxide synthase and cyclo-oxygenase: Interactions between nitric oxide and prostanoids. Br J Pharmacol 114: 1335-1342, 1995.

33. Aparicio-Soto M, Sanchez-Hidalgo M, Cardeno A, Rosillo MÁ, Sánchez-Fidalgo S, Utrilla J, Martín-Lacave I and Alarcón-de-la-Lastra C: Dietary extra virgin olive oil attenuates kidney injury in pristane-induced SLE model via activation of HO-1/Nrf-2 antioxidant pathway and suppression of JAK/STAT, NF- $\kappa$ B and MAPK activation. J Nutr Biochem 27: 278-288, 2016.

34. Schindler C, Levy DE and Decker T: JAK-STAT signaling: From interferons to cytokines. J Biol Chem 282: 20059-20063, 2007.

35. Luo X, Zhang H, Wei X, Shi M, Fan P, Xie W, Zhang Y and $\mathrm{Xu} \mathrm{N}$ : Aloin suppresses lipopolysaccharide-induced inflammatory response and apoptosis by inhibiting the activation of NF- $\kappa$ B. Molecules 23: E517, 2018.

36. Han W, Li H, Cai J, Gleaves LA, Polosukhin VV, Segal BH, Yull FE and Blackwell TS: NADPH oxidase limits lipopolysaccharide-induced lung inflammation and injury in mice through reduction-oxidation regulation of NF- $\kappa \mathrm{B}$ activity. J Immunol 190: 4786-4794, 2013.

37. Pan JS, Hong Mz and Ren JL: Reactive oxygen species: A double-edged sword in oncogenesis. World J Gastroenterol 15: 1702-1707, 2009.

38. Park SK, Dahmer Mk and Quasney MW: MAPK and JAK-STAT signaling pathways are involved in the oxidative stress-induced decrease in expression of surfactant protein genes. Cell Physiol Biochem 30: 334-346, 2012.

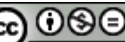

This work is licensed under a Creative Commons Attribution-NonCommercial-NoDerivatives 4.0 International (CC BY-NC-ND 4.0) License. 